\title{
Barbara RATZENBÖCK*
}

\section{"Let's Take a Look Together": Walking Interviews in Domestic Spaces as a Means to Examine ICT Experiences of Women $60+{ }^{1}$}

\begin{abstract}
Although mobile methods are becoming more common within the social sciences (e.g. Ricketts Hein et al., 2008 and Wiederhold, 2015, p. 607), they mostly take place outdoors. This paper examines the potential of walking interviews conducted in small domestic spaces to explore the ICT experiences of women aged 60+ and to discuss the challenges and advantages of this method. This case study of indoor walking interview material is a part of a larger research project on the ICT experiences of women 60+ in the Austrian province of Styria. The advantages and challenges of conducting walking interviews in the homes of interviewees are identified and explored. As this case study demonstrates, walking interviews in homes give the researcher a glimpse into the private areas of everyday life, let the interviewees lead the researcher through the space, allow the participants to conduct the conversation, and thus invite a reflection on the power dynamics inherent in the interview situation. This method also compares the statements provided by participants in semi-structured interviews with the information gathered through an encounter with media and ICTs in the home. These comparisons yield a variety of insights on prior statements through the addition of emphases, "contradictions," or minimizing the importance of previous interview statements. Moreover, interactions with the objects in the home that are encountered during the walking interview also provide important "prompts" to stimulate a detailed and multifaceted discussion of everyday life experiences with ICTs and other media.
\end{abstract}

Keywords: mobile methods; indoor walking interview; domestic space; older female ICT users; aging.

\section{Introduction}

During the past several years, mobility research and issues of mobility have become central topics within the social sciences (e.g. Ricketts Hein et al., 2008 and Wiederhold, 2015, p. 607). More and more research projects "are seeking to bring mobility into the research process, particularly in the investigation of 'everyday' life practices and lifeworlds", as Ricketts Hein et al. (2008, p. 1266) explain. However, walking interviews (e.g. Jones, Bunce, Evans, Gibbs \& Ricketts Hein, 2008) are still a comparatively recent qualitative method within the social sciences. In walking interviews the interviewer and interviewee are in movement while they converse. During these mobile conversations, the surroundings often act as stimuli for discussion (Anderson, 2004, p. 257). Disciplines such as cultural geography and ethnog-

*University of Graz, barbara.ratzenboeck@uni-graz.at.

${ }^{1}$ Acknowledgement note: Supported by funds from Oesterreichische Nationalbank (Oesterreichische Nationalbank, Anniversary Fund, project number: 15849). 
raphy regularly employ qualitative research methods and have developed the concept of mobility in the context of qualitative research. In ethnography, for example, Kusenbach (2011) has developed the "go-along" method. According to Kusenbach (2011, p. 184), go-alongs constitute "a hybrid between participant observation and interviewing." Although mobile methods were already being used repeatedly to investigate "'everyday' life practices and lifeworlds" (Ricketts Hein et al., 2008, p. 1266), the interviews mostly took place in outdoor contexts. Examples include, among many others, studies conducted by Doughty (2013), Jones et al. (2008) or Anderson (2004). The use of walking interviews within people's homes, however, seems to be less common. This, Roberts ${ }^{i}$ notes (personal communication, July 23, 2014), has resulted in a gap in research literature on the topic.

This paper examines the potential and the challenges of walking interviews conducted in small domestic spaces to explore the information and communication technology (ICT) experiences of women aged 60 plus. It is important to note that the walking interviews are one part of a three-part methodology used in this larger research project, which also includes life-graphing and semi-structured interviews. The results of these other methodologies are not the focus of this paper, but they are used to provide $a$ context for the discussion of the indoor walking interviews.

\section{Examining the ICT Experiences of Women 60+}

As everyday life in private spaces and public arenas is permeated by an increase in the number of information and communication technologies (ICTs), as well as media devices, questions of unequal access and competencies related to ICTs become crucial. Access and competencies often define opportunities for participation in social, cultural, economic, and political spheres. Reflecting on these opportunities or blockages to participation in the world of ICTs and on "skilled access" (Garson, 2006) when using ICTs, the current empirical study investigates the use of ICTs by older women in Austria, a group significantly affected by the socalled digital divide (e.g. Doh, Wahl \& Schmitt, 2005, p. 36) in terms of Internet usage (Statistik Austria, 2015). Specifically, this case study explores how women from various socio-economic backgrounds, between the age of 60 and 70, and residing in the Austrian province of Styria, ${ }^{\text {iii }}$ have been using and have ascribing meaning to ICTs throughout their lives. In doing so, the study explores continuities and changes in strategies of ICT usage over the life course.

\section{Theoretical Framework}

Karl Mannheim's (1952) notion of "generation location," Burkhard Schäffer's (2009) concept of "generation-specific media practice cultures,"iv and Roberta Maierhofer's $(1999,2004$, 2007) term "Anocriticism" provide theoretical tools to investigate how interview participants have been using and ascribing meaning to ICTs throughout their lives. According to Mannheim, youth experiences are particularly influential on the formation of general attitudes and perceptual patterns. Youth experiences lead to what Mannheim terms a "similarly 'stratified' consciousness" (1952, p. 297) of a generation. Mannheim's idea of "generation location" is used in the analysis of this empirical material to examine, specifically, the generational aspects of ICT usage by women 60+. In a similar way, Schäffer's (2009) idea of "generationspecific media practice cultures" is used to investigate generation-specific practices in the 
context of ICTs, such as the carefully planned execution of actions in opposition to "trial and error approaches."v In addition to Mannheim's perspective, which emphasizes the influence of a person's experience in their youth on their observations and interpretations later in life, Maierhofer's $(1999,2004,2007)$ concept of “Anocriticism" is used to investigate the influence of individual (media) biographies and practices. Anocriticism is "an interpretational approach that validates individual experience of age and aging in resistance of normative assumptions" (Center for Inter-American Studies, 2015) and emphasizes the diversity of life course experiences as well as the difference between chronological age and cultural assumptions associated with age (Maierhofer, 2007, pp. 111-112). ${ }^{\text {vi }}$ While Mannheim's notion of "generation location" emphasizes the importance of collective experiences within time, Maierhofer's analytic lens of "Anocriticims" draws attention to the individual interpretation of life course experiences.

\section{Study Design and Methodology}

In comparison to the research that has been done on the media biographies of young people, less research has been done on older adults (Vollbrecht, 2009, p. 23). For this reason, this case study adopts an exploratory qualitative research design to investigate the ICT experiences of women $60+$. A starting point for the overall study emerged from the idea that ICT devices might change more rapidly over decades while basic modes of interaction are perhaps more stable; thus, a broad definition of ICTs, inclusive of other media, has been adopted to allow for a comparison of media experiences and strategies of use across different devices. Referring to a definition suggested by the United Nations Development Programme (2001), this study conceptualizes ICTs as comprising both new ICTs (e.g. the Internet) and older ICTs, such as radio, sound-systems, and television.

In order to investigate the strategies of use and the processes deployed by older women to ascribe meaning to ICTs, this larger research project employs three qualitative research methods: life-graph discussions ${ }^{\text {vii }}$, sedentary semi-structured interviews, and indoor walking interviews. While life-graph discussions serve as a means to emphasize a life course perspective in the conversations, the semi-structured interviews focus on a variety of topics that are relevant to the usage of ICTs. Semi-structured interviews, for example, bring forth media-biographic memories, strategies of usage, and attitudes towards various kinds of ICTs (computers, the Internet, cell phones, TV, and radio). viii The indoor walking interviews in the homes of the interviewees are then employed to explore more implicit aspects of media practices and experiences. This larger research project uses the Grounded Theory approach (Strauss \& Corbin, 1990) to examine these different phases of data collection and analysis, regularly alternating the collection and the analysis of the data. An open coding approach, as described in Grounded Theory (Strauss \& Corbin, 1990), was applied to most of the analysis of the empirical material collected.

\section{Initial Findings from the Broader Research Project}

To date, five lengthy, semi-structured interviews, five walking interviews, and life-graph discussions ${ }^{\mathrm{ix}}$ have been conducted and analyzed. The first interviewee was contacted by a fellow researcher at the Center for Inter-American Studies which lead to the snowball recruitment of further participants. 
The preliminary findings obtained through the analysis of the material thus far shows that both generation-specific media practices as well as individual media biographies affect the way in which the participants use and ascribe meaning to ICTs. In terms of generational elements, generation-specific media experiences and strategies of ICT usage as well as intergenerational experiences are relevant. In the context of generation-specific media experiences, early-life experiences with ICTs are especially important to highlight. Examples include childhood rules for interacting with ICTs (e.g. the rule to "not break media devices"), experiences of collective media interactions (e.g. collective TV-watching with neighbors), as well as war and post-war experiences related to ICTs (e.g. the radio as source of bad news). The importance of the way in which early-life experiences frame ICTs during other life phases affirms to some extent the relevance of Mannheim's (1952) idea of "generation location." Regarding generation-specific strategies of ICT usage, the notion of "guided and planned execution of actions" is important and supports the results Schäffer obtained from his 2009 study. Participants also repeatedly mention strategies of preserving, saving, and passing on of materials that were produced with the help of ICTs; for example, photographs. However, the most dominant theme is intergenerationality. A wide variety of intergenerational experiences were shared in the conversations but these stories often focus on the help participants receive from their sons and/or the means through which their sons help them to acquire their ICT devices. The stories about the participants' intergenerational interactions with ICTs are salient in terms of gender and in reference to other studies on seniors' usage of ICTs as they support the findings of previous studies conducted in other countries, such as those of Crow and Sawchuk (2015, p. 196), on the use of mobile devices by Canadian seniors. This will be discussed in more detail later in the paper.

With regard to more individual elements of ICT usage and media biographies, participants shared a variety of stories that reflect the individuality of their life experiences. However, one dominant theme across all conversations is the relevance of previous work experiences and the way in which these experiences influence the way in which participants currently use and think about ICTs ("new" ICTs in particular). Another topic worthy of note is the interviewees' reflections on the way in which their own ICT usage changed due to changes in location, e.g. in the context of trips for medical rehabilitation. For the most part, however, stories on individual experiences of ICT usage reflect the diversity of life course experiences and individual relevancies, such as political or leisure interests.

\section{Painting a Fuller Picture: ICT Usage by Women $60+$ and the Indoor Walking Interview}

Following this brief outline of the initial findings from the larger research project, particularly from the semi-structured interviews, the subsequent sections discuss how walking interviews in small domestic environments can help researchers to understand a lifetime of experiences with ICTs. As the initial results of this study demonstrate, walking interviews conducted in domestic spaces may lead to more complex and more personal accounts of everyday life experiences, thus providing "thick description" (Geertz, 1973) of these experiences. 


\section{Interviewing as "Travelling" and Presentation as "Storytelling"}

To frame the discussion of the indoor walking interviews, it is important to address the underlying epistemological assumptions of (walking) interviews. While some interview studies and walking interview studies allude to what Kvale (2007) labels the "minor metaphor" in terms of epistemological assumptions, this case study explicitly draws on Kvale's notion of interviewing as "traveling." Thinking of the interview process as "mining" means conceptualizing knowledge as something "waiting in the subject's interior to be uncovered, uncontaminated by the miner" (Kvale, 2007, p. 19). Such notions of qualitative research as "mining" do not necessarily refer to mere positivist understandings of qualitative research, but can, for example, express a psychoanalytical understanding of the research process as a "quest for the hidden meanings in the unconscious" (Kvale, 2007, p. 19). Thinking of qualitative research and indoor walking interviews not as "mining," but instead as "travelling" (Kvale, 2007, p.19) emphasizes the pluralities of meaning and generates a fuller picture of everyday life experiences. As Kvale (2007, p. 19) puts it, "[t]he interview traveller, in line with the original Latin meaning of conversation as 'wandering together with', walks along with the local inhabitants, asks questions and encourages them to tell their own stories of their lived worlds." Rather than looking for "authentic meanings," the interview traveler is interested in "potentialities of meanings," interpretations and narratives (Kvale, 2007, p. 19). Building on such an understanding of knowledge production, one can also think of the qualitative researcher as "researcher-story-teller" (Brown, 2010), as someone telling empirically-grounded "stories" about social realities. ${ }^{\mathrm{x}}$ In what follows, the findings obtained through indoor walking interviews are presented by telling stories: the stories of women living in the province of Styria in Austria, all of whom are aged 60 or older. The participants' stories about their experiences with ICTs provide insight into how the walking interviews in the home offer the researcher and the participant the opportunity to co-create rich and multidimensional narratives on ICTs.

\section{The Indoor Walking Interview}

Indoor walking interviews are very loosely structured interviews that are conducted during walks with the participants in their homes. In my project, these indoor walking interviews occurred after the life-graph discussions and the semi-structured interviews. After conducting $a$ sedentary semi-structured interview on the same day, the researcher and the participant begin the walk through the house to discuss the interviewee's media devices. It is important to note that, at this point in time, the researcher suggests "Let's take a look together at all media devices at the house, if this would be okay"xi to check in and to ensure that the participant is comfortable with the walking interview. Under the lead of the interviewee, who sets the pace and route for the joint tour through the apartment or house, the interviewee and interviewer walk through the different rooms and eventually stop when the interviewee points out an ICT device. At this point, the interviewees immediately may begin to elaborate $a$ story about the device. If not, then the interviewer may acknowledge the presence of the device by saying something like "So this is your TV-set/ your radio/ your computer" etc. and then ask the interviewee to comment on the device. As a stimulus for the commentary, the interviewer poses very general and open-ended questions, such as "What does this TV-set/ radio/ computer look like to you?" or "Where is this positioned?". After a short conversation about the device, the interviewer will usually ask the interviewee to turn $i t$ on and to elaborate on 
what they usually do with it. The interviewer then asks the interviewee for permission to take photos of the ICT devices presented. The photos primarily serve as a memory-aid for the interviewer later on, but sometimes the photo-taking prompts the interviewees to explain the device in more detail or to show additional functions or features.

\section{Challenges in the Context of Walking Interviews in Domestic Spaces}

While some advantages of walking interviews in small domestic spaces are rather intuitive, as will be discussed below, the challenges of indoor walking interviews are more difficult to pin down. In general, the practicalities regarding mobile methods are an issue. Researchers perform a multiplicity of tasks simultaneously, such as carrying a recording device in motion, watching their step and direction, formulating questions and listening attentively to the stories of the interviewees. As Hall et al. (2006, p. 3) state: "movement puts the interview at risk [...]; it exposes the interview to interruption, it ratchets up the ratio of noise to signal." In addition, walking interviews - similar to other empirical methods - are more suited for the investigation of some topics than others. Mobile methods in general are wellsuited for exploring a range of specific topics such as special practices, engagement with the environment or biographies, as Kusenbach (2011, pp. 187-197) convincingly outlines in the context of the "go-along." However, mobile methods are less suitable for the exploration of topics such as group values, which can be better explored in group discussions (Bohnsack, Przyborski \& Schäffer, 2007, p. 7).

Another challenge, which is particularly relevant for walking interviews conducted in small domestic environments, is the subtle negotiation of privacy and trust as researcher and interviewee move through the bedrooms and bathrooms of the interviewee, which are very personal and intimate private spaces in a home. The particular significance of privacy and trust is highlighted by the fact that four out of five participants chose to show their bedrooms last or second to last during the interview. Only one interviewee did not include the bedroom in the tour. Bathrooms were only included in the tour by one participant, but this might also be because ICT devices are less common in Austria in bathrooms than in bedrooms, where, for example, a TV or radio alarm is often situated. Sometimes the participants negotiated trust and privacy in subtle ways; other times, these negotiations were more explicit. For example, Interviewee five (I-5) expressed worries that the bed in the bedroom might not be made. On other occasions, the participants addressed tidiness and housekeeping during the tour. One participant (Interviewee four) explained that she puts a kitchen towel on the printer in the study so that it does not collect dust and was then quick to add "This doesn't mean I don't want to clean." This example illustrates the importance for the interviewer to convey that they will not impose any judgments on the organization of everyday private life but want to learn more about practices and objects of the interviewee's everyday life through the joint tour of the house.

As Elwood and Martin (2000, p. 650) point out, interviews represent socio-spatial relationships on a small scale, they produce their own "microgeographies" and "reflect the relationships of the researcher with the interview participant, the participant with the site and the site with the broader sociocultural context that affects both researcher and participant." The socio-spatial situated-ness and interconnectedness of the interview site, as well as the proximity of the participant and the researcher were crucial to this study. For example, the participants make recurrent references to housekeeping during the home tours. These comments are not surprising, given that women in Austria continue to do the majority of unpaid work, 
such as housekeeping (Gender Equality in the Labour Market, 2010, p. 18). All of the participants and the researcher are women; thus, the references made by the interviewees contribute to sense-making in $a$ cultural environment where the home has been constructed as a place where the expectation, culturally, is that women will care for it.

\section{Advantages of Walking Interviews in Domestic Spaces}

Although negotiations of privacy can be a challenge, the closeness to private, everyday life and its objects constitutes one of the very advantages of (walking) interviews conducted in domestic spaces. First, being at the homes of the interviewees allows for family-related and household-related themes to be elaborated on extensively. As Sin (2003, p. 306) has noted, "[i]nterviews are, at least in part structured by the spatial context in which they are conducted." This was made apparent when participants would share family-related stories on ICT usage (e.g. on intergenerational ICT experiences). In this study, the interview site thus helped to foreground the social and familial embedded-ness of the ICT usage of the participants.

Secondly, conducting interviews in the home context allows for the participation of interviewees who are less mobile or flexible in terms of location, be it in terms of $a$ health condition, geographical location, or care and family responsibilities. This has also been illustrated by $\operatorname{Sin}(2003$, p. 308) in the context of health status. In this study, multiple Interviewees (three, four, and five) had been responsible for family responsibilities during the day (e.g. watching grandchildren, cooking for (extended) family, household work), so the home as an interview location seemed to allow participants to take more time for the interviews. With the interview taking place in their home, they could take breaks from it in order to put a dish in the oven or to talk to one of their grandchildren. Interviewee three voiced this advantage explicitly by calling her friend on the phone to recommend participating in the study. As she exclaimed: "This is great. You can even get your cooking done during the interview."

The closeness to the private and family-related aspects of everyday life and the potential inclusiveness are not only advantages of walking interviews, but of any interview conducted at home. So what does joint walking in the home add to the research process? First, the movement through different rooms in the house provides the researcher with the opportunity to observe the interactions of participants with everyday life objects at their homes. In the context of this study, the indoor walking interviews were a suitable means of exploring how informants act "together with" ICTs, if we - following Latour (1993, p. 55) - conceptualize ICTs as "quasi-objects." This interview style also helps draw attention to the fact that media technologies themselves incorporate habitual aspects, for example with regard to design and usability (Schäffer, 2009, p. 43), and influence how individuals interact with them. In this way, interaction with objects during the tours allowed for the expression of non-verbal forms of knowledge, for example of routines and implicit knowledges, which are more difficult to verbalize during a sedentary face-to-face interview situation. The house tours thus allowed for different ways of expressing experiences; in particular, showing instead of telling.

Secondly, the physical shifting of perspectives during the home tour allowed participants to "complicate" their stories. If walking interviews are conducted subsequent to other conversations (in this case, the life-graph discussion and the semi-structured interview), they may provide study participants with the opportunity to emphasize, "contradict, "xii weaken or add to statements made earlier. While this certainly is not a unique feature of indoor or outdoor walking interviews, it emphasizes advantages of a multi-method approaches in general. A multi- 
method approach often gives more space to participants to share their stories. However, the physical shifting of perspectives by walking through several rooms during the walking interview in the homes of participants seems to support a simultaneous shifting of perspectives and reflections on ICT-related issues. Anderson (2004, pp. 257-258) and Ricketts Hein et al. (2006, p. 1277) make a similar point in their discussion of the walking interview. Specifically, Ricketts Hein et al. (2006, p. 1277) argue that "[w]alking, like telling stories, is the movement between places [...]." Thus, walking interviews can, in a very literal sense, shift perspectives of participants and allow them to share stories that are more contradictory or complex. Ultimately, such perspectives contribute to richer accounts of experiences.

Hall, Lashua, and Coffey (2006, p. 3) suggest that walking interviews "even out some of the power differentials which even the most informal of interviews can struggle to throw off." Similar observations were also made by Anderson $(2004$, p. 258) and can certainly be acknowledged as being important to his study. Participants often seemed to be more open and willing to elaborate their thoughts during the walking interviews. This is noteworthy since the preceding life-graph discussions and semi-structured interviews also took place in their homes. This is likely because interviewer and interviewees have had some time (approximately two hours) to get to know each other. It may also be because the interviewees lead the walking interviews through their homes bringing about a more balanced power situation. As Hall et al. (2006, p. 3) write: "Leading the way, interviewees can shift the discussion from description to personal commentary and back, as it suits them; if the talk takes a wrong turn, diversions are at hand." The walking interviews in this study resemble a normal tour of a house that might be offered to $a$ visiting relative or neighbor. The walking tours thus allude to a common form of social interaction that is less hierarchical than traditional, face-to-face sit-down interviews. For the most part, interviewees seem to enjoy the walking interview and to be pleasantly surprised that the interviewer genuinely is interested in their way of living at home.

The walking interviews at home allow for a less-hierarchical interaction during the interview process and provide the researcher with glimpses of what Goffman (1956) calls the "backstage." This is that place and that moment where interactions are more informal and it is easier to make "contradictions," reinterpret or add to one's stories. As explained earlier, walking interviews in homes are not entirely void of power dynamics. The interviewer is still a visitor who should not, for example, see an unmade bed if the interviewee decides. However, the physical movement through the home means that the interviewees do not need to get stuck in moments of discomfort; walking can allow them to move on and to shift their perspectives on the content, as the subsequent discussion of walking interview material demonstrates. If asked what the particular advantage of walking interviews in domestic homes is, one could answer that it is the combination of: being granted access to parts of the "backstage" (Goffman, p. 156); allowing interviewees to exist in $a$ position in which they get to decide when to shift perspectives, either by controlling the movement through the home or by or shifting the emerging content by changing the context and prompting the interview to move on. In this way, participants paint a "fuller picture" of their everyday life experiences with ICTs. 


\section{Highlighting Statements, Negotiating Experiences, and Shifting Perspectives: Preliminary Findings from the Indoor Walking Interviews}

Drawing from examples from the walking interview material, the subsequent discussion focuses on how indoor walking interviews allow interviewees to highlight and negotiate their ICT experiences and to shift their perspectives. It shows how interviewees use the walking interviews to emphasize themes or stories that are important to them; to add new aspects not mentioned before; to "contradict" or weaken statements made earlier (during the preceding life graph discussions and semi-structured interviews); or to introduce entirely new ideas. It also demonstrates how indoor walking interviews allow the interviewees to interact with ICT devices.

\section{Highlighting Statements: Emphases of Experiences}

During the walking interviews, all five participants emphasized the relevance of themes or statements mentioned during the preceding life-graph discussions and semi-structured interviews. One example illustrates the gender-related connections and expectations that the participants have in their understanding of ICTs and expertise. In the semi-structured interviews, four out of five interviewees shared stories explaining how their sons regularly help with the use and/ or acquisition of ICT devices. As mentioned earlier, this is an interesting finding with respect to gender and ICTs. Most of the participants have daughters or daughters-in-law (sometimes even living in the same house) who could potentially help them trouble-shoot their ICTs. However, with the exception of one interviewee, the participants $\mathrm{d} o$ not mention their daughters as ICT helpers. Interestingly, in the indoor walking interview, the importance of the son as a helper is underscored by three out of four interviewees $(I-2, I-4$, I-5) who also address this topic in the semi-structured interview. To use an example from the interview material: Interviewee four (I-4), a woman in her mid-sixties from a small village in southern Styria who had worked as an accounting clerk before retirement, emphasizes the importance of her son as an ICT helper in the semi-structured interview: "Thank goodness that I have a son; when I didn't know about something or when we [her and her husband] didn't know about something, then we get him [laughs], he then has to fix it [the computer] again, when something is broken or whatever." In the walking interview in the home, while standing in front of the computer in the study, I-4 elaborates by giving a concrete example of how her son provides help with her ICTs. Pointing at the computer's personalized desktop background, a picture of a landscape in the spring, she exclaims: "[He] set this up, so everybody has their own [background image], because otherwise you keep searching. Everybody has got something else." This example underscores the general importance of her son as an ICT helper but, at the same time, sheds light on what she means when stating that "he has to fix [...] whatever" (own emphasis). In this case, the son is not only being consulted when hardware is broken or advice on a program is needed but also assists with organizing more common settings, such as the desktop.

Negotiating Experiences: New Interpretations, "Contradictions" and Minimizing Importance

While I-4 provides a concrete example for the help of her son with ICTs in the example cited above, Interviewee five (I-5), a 62-year old woman from a small city in Upper Styria 
who apprenticed as a seamstress but has been a family manager for most of her life, emphasized the important role her son plays in her relationship to ICTs. During the semi-structured interview, she elaborates the ways that her son helps with various ICT interactions (e.g. searching for things online because he is "faster and more competent"), and she explains that he has handed down his old computer to her and her husband. Later, in the walking interview through the house, she emphasizes the influence of her son in ICT matters. Standing in front of her TV-set in the large living room, she states: "And I actually didn't want it [the TV-set] to be as big and I wasn't there [at the electronics store]. [My son] of course was there and they [her husband and her son] took the bigger one, of course." Notably, I-5 finds it natural (she says "of course") that her son, together with her husband, are deciding what TV-set should be bought for her and her husband's household. Interviewee five also talks about her son's involvement with ICTs in $a$ less than positive light when she frames the TV as something she actually "didn't want." This detail is notable. The majority of stories about "the helping son" are framed very positively across all interviews. ${ }^{\text {xiii }}$ Thus, the walking interview conducted in the homes of interviewees may support the discovery of "potentialities of meanings" (Kvale 2007, p. 19) - in this case in the context of stories on gendered intergenerational relationships and expectations with respect to ICTs. It also exemplifies how the literal shifting of perspectives during the walking interview in the homes of the interviewees may contribute to a simultaneous shift in terms of content, a point Ricketts Hein et al. (2006, p. 1277) have made discussing walking interviews.

Other parts of the walking interview material illustrate how previously-made statements may be weakened in terms of significance or "contradicted." Compared to statements that are either emphases of previously-made statements or the introduction of new aspects of ICT experiences, these two categories of statements are not as empirically present. It may be easier to recognize themes that have been deemed less important or „contradictions" in statements. An example of a previous statement that had been minimized or tempered is a story shared by a 60-year-old former secretary and family manager living in a suburb of Graz (I3). In the semi-structured interview, I-3 described her usual handling of new ICTs: "And this is always at the back of my mind, that you should not break anything. It is idiotic, I know very well that I won't break anything, but it doesn't work anyways. I prefer asking first and then I do it." During the joint inspection of her mobile phone during the walking interview, however, she states that she changed the size of characters on her phone display by just trying and finding out "by accident": "There, I tried and then I saw that you can [put] bigger characters. [...] I did this myself." While at some points during the semi-structured interview, she briefly mentions that she "occasionally" tries out things herself, this $i s$ the only concrete example she provides which weakens her previous statement of "not just trying out things."

Regarding "contradictions" of previously made statements, an illustrative example from the current analysis is an account of I-5, a woman who identifies as a non-user of computers and the Internet. In the semi-structured interview, she frames computers and the Internet, on the one hand, as a waste of time and, on the other, as a necessity for work. For instance, she states: "Of course, if you need it [the computer] for work, as it is everywhere today, it is great and everything is faster [...], but for us this is not essential anymore [...]. [W]e don't need the computer, not necessarily, right, something like the Internet." In the walking interview through the home, however, she mentions that her husband often goes to "play on the computer" in the evening while she reads or goes to sleep, only to shortly afterwards correct herself and say that she did not mean that he literally plays computer games, but that he looks 
up some things that are related to his former job as an alpine tour guide. This is a significant addition or perhaps more accurately a "contradiction" of her previous description of the computer and the Internet as things primarily related to work. It also explains why she thinks that computers and the Internet are a waste of time: she sees them as something similar to kids' toys, as something you should not bother with as an (older) adult.

A "contradictory" aspect of another interviewee's $(I-1$ 's) relations to ICTs was shared during the walking interview. Interview one is a 66 year-old woman from the suburbs of Graz, who had worked part-time as a secretary in the public sector and continues to be the family manager. During the walking interview, she first speaks about the TV-set in the living room and then suddenly turns to an amplifier and stereo next to it to point out the record player on top of the stereo. She then compares records to CDs, eloquently elaborating on the high acoustic quality of the music on the records. She then shares an example of "that (!) difference" between music on CDs and records. During the minutes that follow, I-1 continues to play a variety of pieces of music recorded on records to emphasize the wonderful quality of music that records provide. Her comments on the quality of the music are informative as she introduces a device that is of obvious importance to her: her stereo. She also expresses the bodily dimension of her interaction with this particular media device. As she puts it, listening to records gives her "the goosebumps." The most valuable part of this interaction is a comment she makes on her general technological skills. Getting ready to play the next piece of music on the record player, I-1 states: "Alright, this I can even handle! Well, I even know how to lift that thing [the needle of the record player]. Well, this dates back to my youth." This statement is vitally important to interpret. During the semi-structured interviews that had been conducted earlier, I-1 repeatedly presented herself as "a strong user" of new ICTs. However, during the walking interview, she demonstrates and expresses considerable insecurities while handling a range of ICTs, except for her sound system.

Another particularly illustrative example in the context of "contradictions" is the competency that Interview three exhibits while handling the computer during the walking interview. In the semi-structured interview, this participant talked extensively about the computer programs she used at work prior to retirement and yet continually played down her computer competencies by offering stories about the ways that her son helps with new ICTs. Her actual expertise in interacting with computers, however, is demonstrated in the walking interview. Interacting with the computer, she skillfully uses various key combinations (shortcuts) to successfully enter commands. This observation highlights the potential downplaying of ICT skills by the women interviewed and draws attention to social norms and cultural narratives associated with aging and gender. It also highlights the importance of "Anocriticism" (Maierhofer, 1999, 2004, 2007) as an interpretational approach for the analysis of the material. It draws attention to normative assumptions with regard to age and aging in cultural representations, such as this interview material. This example also underscores an advantage of conducting walking interviews in homes as a method to examine everyday life experiences and ICTs. Walking interviews allow interviewees to express their experiences verbally, but also to show instead of just tell.

\section{Shifting Perspectives: Introduction of New Aspects of Use}

Aside from emphasizing previously made statements or negotiating them, the walking interviews often were used by participants to introduce entirely new aspects of ICT usage and 
experiences, which they had not mentioned earlier. In this context, one could argue that the participants' interactions with devices serves as a stimulus for further discussion. Examples from the transcriptions are numerous. For example, an interesting story by I-4 surfaces in the walking interview, when our encounter with the landline telephone prompts her to reveal that she and her husband rarely use it. She further explains that the only time they use it is when somebody calls them. As she elaborates looking at the landline phone, her older sister, in contrast, mostly uses the landline. She then reflects on this in detail:

My sister for example, she is still used to calling on the landline, yes, because the number is shorter or I don't know. [...] [I]t is funny, [...] she [her sister] always calls me on the landline, apparently this is so deeply internalized by her [literally: "deep inside of her"], the landline phone number. She always knows that one by heart and a cell phone number is just inconvenient for an older person. [...] [I] don't know for how long we have been having this landline already, 30 years or something? And this sticks, while these days, a cell phone number doesn't mean anything to anybody. Actually, every few years you can get a different number; this is why I guess that she likes to call on the landline.

This statement is very informative as she herself introduces the idea that ICTs and people can be deeply connected and interact in a very literal way. More precisely, she thinks that things, such as a phone number, can become part of a person: the landline phone number is "deep inside" of her sister. This statement is reminiscent of Latour's argument that technology is a "quasi-object," "a moving actant that transforms those who do the moving, because they transform the moving object" (Latour, 1996, p. 379). This example further demonstrates how the presence of media and technology devices encountered during the walking interviews at home may lead to processes of extensive reflection and to new perspectives on experiences and objects.

\section{Conclusion}

As the above analysis indicates, walking interviews that are conducted in small domestic spaces allow for a joint exploration of "potentialities of meanings" (Kvale, 2007, p. 19) of a subject by interviewer and interviewee. They can lead to relevant empirical material and reveal everyday life experiences and nuance the researcher's understanding of their participants' engagements with ICTs. The main advantages of this method are that it addresses some of the power imbalances in interview situations by letting participants shift directions and perspectives at any point and that it allows the researcher to get glimpses of some of the "backstage" areas of everyday life (Goffman, 1956). It thus invites researchers to reconsider new emphases, "contradictions," to lessen the import of previous statements, to generate insights on the devices discussed on location and may stimulate ideas for further reflection. During walking interviews in domestic spaces, objects are invited into the research process where they may prompt a more detailed and multifaceted discussion of everyday life experiences and the complex and nuanced entanglements with media and ICTs. As Wiederhold (2015, pp. 612-613) succinctly puts it, albeit in another context: "Mobile methods deviate from more traditional approaches to interviewing by inviting disruption, serendipity, and unplanned interactions [...]." In the context of walking interviews at home, the on-site interaction with everyday life objects, such as ICTs, can help to nuance the stories of participants through "contradiction" and rich detail. This is crucial for the telling of empirically-ground- 
ed complex "stories" about the lived ICT experiences of these interviewees. It supports the exploration of cultural narratives that inform everyday life practices related to media and their representation in controlled research environments, as the example of I-3 and her (non-verbalized) mastering of shortcuts illustrates. The walking interviews that are conducted in the homes of the participants also contribute to a fuller understanding of the importance of gendered intergenerational relationships in the ICT context and the complexity of these relationships, as the story of the unwanted big TV shared by one interviewee (I-5) reveals. In conclusion, walking interviews conducted in the homes of the participants are a potentially productive approach to understanding the role of ICTs in everyday life. In this case, this method draws attention to the multidimensionality of the ICT experiences of women $60+$ and, most importantly, points to the on-going need for researchers in age/aging studies to create empirically-grounded stories that may counter the one-dimensional cultural images of older women and ICT use.

\section{Notes}

${ }^{i}$ Thomas Roberts is a research fellow at the Centre for Research in Social Simulation (CRESS) at the University of Surrey.

ii This study belongs to the research project "Cultural Narratives of Age and Aging," a project located at the Center for Inter-American Studies of the University of Graz, Austria and directed by Roberta Maierhofer (supported by funds from Oesterreichische Nationalbank, Anniversary Fund, project number: 15849).

iii The reason behind limiting the age range was the need to create a comparable group of participants. In Austria, the Internet became more widely accessible shortly after the turn of the millennium (GfK Austria, 2012, p. 2). Thus, women now aged 60 to 70 are likely to have been engaging with new ICTs such as the Internet on a discursive or a practical level already during their careers, if they were employed before retiring. The limitation of geographical radius is based on the fact that Styria is one of the three Austrian provinces which are close to the overall Austrian percentage of Internet users (Statistik Austria, 2012). Thus, the province of Styria can be considered a good vantage point for the investigation of the interaction with "new" ICTs in Austria since the study - although including a broad variety of ICTs for reasons of comparability - focuses on the usage of "new" ICTs in particular.

iv Translated into English from Schäffer's (2009) original German expression "generationsspezifische Medienpraxiskulturen" by the author of this paper.

${ }^{v}$ In an empirical study from 2009, Schäffer investigated media practices and attitudes towards different types of media among various age groups. In this study, Schäffer showed that older participants (the oldest participant group was aged 60 to 70 ), were more likely to prefer carefully planned and executed actions to "trial and error" approaches when engaging with new media devices.

vi The adoption of a biographical and life course perspective is crucial, as previous studies on the usage of ICTs by seniors have shown; one of them is a case study conducted by Fernández-Ardèvol and Arroyo Prieto in 2012. In their case study on the adoption and use of mobile telephony by seniors in Barcelona and its metropolitan area, Fernández-Ardèvol and Arroyo Prieto (2012, p. 20) have shown that the expert (highly informed) use of mobile telephones is related to an already existing and lifelong strong interest in technology. Regarding the importance of previous life course experiences related to information and communication technologies, the analysis of the overall empirical material of this study gathered so far has led to similar results.

vii Life graphs are graphic representations referring to life course experiences over time in a particular context, and in this study they are drawn by research participants themselves prior to the interview appointment. On the x-axis, participants can indicate relevant periods of time and on the y-axis they can write down important experiences and events in this time span. In this study, the life graphs drawn by the participants prior to the interview appointment are subsequently used as a starting point for the sedentary semi-struc- 
tured interview on ICT experiences over the life course. For an example of a life graph see: Lancaster University. (2014). Transitions in practice: climate change and everyday life: The shower-bath path. Retrieved July 30, 2014, from http://www.lancaster.ac.uk/staff/shove/exhibits/showerv2.pdf.

viii Some of the specific questions asked in the semi-structured interviews have been adopted - sometimes in close translations and sometimes in slightly modified formulations - from an interview outline developed by Mireia Fernández-Ardèvol for a case study on the adoption and use of mobile telephones conducted in Los Angeles (shared via personal communication, September 29, 2014).

${ }^{\text {ix }}$ All but one participant had prepared a life graph prior to the interview appointment.

x Such empirically-grounded stories can be understood as "broad-form stories" which are used to "illuminate something" (Moon, 2010, p. 28).

${ }^{x i}$ The participants are of course also asked prior to the appointment, whether they would agree to a joint tour of the home after the semi-structured interview.

xii The term contradictions is used with quotation marks in this analysis because contradictory statements made by interviewees are not interpreted as indissoluble contradictions or incompatible, false statements, but rather as different and equally legitimate angles from which empirically grounded "stories" can be told - to return to Kvale's image of interviewing as traveling (Kvale, 2007, p. 19) and Brown's idea of qualitative research as storytelling (Brown, 2010).

xiii Only interviewee two very briefly mentioned at some point that she feels "dependent" on her son in ICT matters.

\section{References}

1. Anderson, J. (2004). Talking whilst walking: A geographical archaeology of knowledge. Area, 36(3), 254-261. DOI: 10.1111/j.0004-0894.2004.00222.x.

2. Bohnsack, R., Przyborski, A., \& Schäffer, B. (2010). Einleitung: Gruppendiskussionen als Methode rekonstruktiver Sozialforschung. In R. Bohnsack, A. Przyborski \& B. Schäffer (Eds.), Das Gruppendiskussionsverfahren in der Forschungspraxis (2nd ed.) (pp. 7-22). Opladen: Verlag Barbara Budrich.

3. Brown, B. [TEDx Talks] (2010, October 6). Brené Brown at TEDxHouston. [Video file]. Retrieved July 14, 2015 from http://www.youtube.com/watch?v=X4Qm9cGRub0Mills.

4. Center for Inter-American Studies. (2015). Anocriticism. A New Approach to Literary and Cultural Studies. Project: Roberta Maierhofer (Publication). Retrieved July 13, 2015, from https://interamerikanistik .uni-graz.at/en/research/intersectionality-aging-studies/anocriticism/.

5. Crow, B., \& Sawchuk, K. (2015). New and Old, Young and Old. Aging the Mobile Imaginary. In A. Herman, J. Hadlaw \& T. Swiss (Eds.), Theories of the Mobile Internet: Materialities and Imaginaries (pp. 187-199). Routledge Studies in New Media and Cyberculture. New York: Routledge.

DOI: $10.4324 / 9781315849850$.

6. Doh, M., Wahl, H.W., \& Schmitt, M. (2005). Medienverhalten der 1930/32-Geborenen unter besonderer Berücksichtigung der Internetnutzung: Befunde der Interdisziplinären Längsschnittstudie des Erwachsenenalters. Spiel, 24(1), 35-66.

7. Doughty, K. (2013). Walking together: The embodied and mobile production of a therapeutic landscape. Health \& Place, 24, 140-146. DOI: 10.1016/j.healthplace.2013.08.009.

8. Elwood, S. A., \& Martin, D. (2000). "Placing" Interviews: Location and Scales of Power in Qualitative Research. The Professional Geographer, 52(4), 649-657. DOI:10.1111/0033-0124.00253.

9. Federal Minister for Women and Civil Service at the Federal Chancellery. (2010). Equality in the Labour Market. National Action Plan. Vienna. Retrieved March 18, 2016, from https://www.bka.gv.at/DocView .axd?CobId $=42528$.

10. Fernández-Ardèvol, M., \& Arroyo Prieto, L. (2012). Mobile telephony and older people: Exploring use and rejection. Interactions: Studies in Communication \& Culture, 3(1), 9-24.

DOI: http://dx.doi.org/10.1386/iscc.3.1.9_1. 
11. Garson, D. G. (2006). Public Information Technology and E-governance: Managing the Virtual State. Mississauga: Jones and Bartlett.

12. Geertz, C. (1973). Thick Description: Toward an Interpretive Theory of Culture. In C. Geertz, (Ed.), The Interpretation of Cultures: Selected Essays (pp. 3-30). New York: Basic Books.

13. GfK Austria. (2012). GfK Online Monitor. 4. Quartal 2011. Retrieved July 10, 2014, from http://www. e-government.steiermark.at/cms/dokumente/10103295_34808287/b8a4cf27/gfk_online_monitor_4_qu_ stand_Juni_2012.pdf.

14. Goffman, E. (1956). The Presentation of Self in Everyday Life. New York: Doubleday Anchor.

15. Hall, T., Lashua, B., \& Coffey, A. (2006). Stories as Sorties. Qualitative Researcher, 3, 2-4. Retrieved July 15, 2015, from http://www.cardiff.ac.uk/socsi/qualiti/QualitativeResearcher/QR_Issue3_06.pdf.

16. Jones, P., Bunce, G., Evans, J., Gibbs, H., \& Ricketts Hein, J. (2008). Exploring Space and Place With Walking Interviews. Journal of Research Practice, 4(2), n. p. Retrieved July 13, 2015, from http://jrp .icaap.org/index.php/jrp/article/view/150/161.

17. Kusenbach, M. (2011). Street Phenomenology: The Go-Along as Ethnographic Research Tool. In P. Atkinson \& S. Delamont (Eds.), Sage Qualitative Research Methods (Vol. II) (pp. 177-204). Sage Benchmarks in Social Research Methods. London: Sage. (Originally published in Ethnography 4(3) 2003, 455485. DOI: 10.1177/146613810343007).

18. Kvale, S. (2007). Doing Interviews. London: Sage.

19. Lancaster University. (2014). Transitions in practice: climate change and everyday life: The showerbath path. Retrieved July 30, 2014, from http://www.lancaster.ac.uk/staff/shove/exhibits/showerv2.pdf.

20. Latour, B. (1993). We Have Never Been Modern (C. Porter, Trans.). Cambridge: Harvard University Press.

21. Latour, B. (1996). On actor-network theory: a few clarifications. Soziale Welt, 47(4), 369-381.

22. Maierhofer, R. (1999). Desperately Seeking the Self: Gender, Age, and Identity in Tillie Olsen's 'Tell Me a Riddle' and Michelle Herman's 'Missing'. Educational Gerontology, 25(2), 129-141. DOI: $10.1080 / 036012799267918$.

23. Maierhofer, R. (2004). The Old Woman as the Prototypical American - An Anocritical Approach to Gender, Age, and Identity. In W. Hölbling \& K. Rieser (Eds.), What is American? New Identities in U.S. Culture (pp. 319-336). Vienna: LIT.

24. Maierhofer, R. (2007). Der gefährliche Aufbruch zum Selbst: Frauen, Altern und Identität in der amerikanischen Kultur. Eine anokritische Einführung. In U. Pasero, G. M. Backes \& K. R. Schroeter (Eds.), Altern in Gesellschaft. Ageing - Diversity - Inclusion (pp. 111-127). Wiesbaden: VS Verlag für Sozialwissenschaften. DOI 10.1007/978-3-531-90416-0.

25. Mannheim, K. (1952). The Problem of Generations. In P. Kecskemeti (Ed.), Karl Mannheim: Essays (pp. 276-322). London: Routledge. (Original work published 1927/28).

26. Moon, J. (2010). Using Story In Higher Education and Professional Development. New York: Routledge.

27. Ricketts Hein, J., Evans, J., \& Jones, P. (2008). Mobile Methodologies: Theory, Technology and Practice. Geography Compass, 2(5), 1266-1285. DOI: 10.1111/j.1749-8198.2008.00139.x.

28. Schäffer, B. (2009). Mediengenerationen, Medienkohorten und generationsspezifische Medienpraxiskulturen. Zum Generationenansatz in der Medienforschung. In B. Schorb, A. Hartung \& W. Reißmann (Eds.), Medien und höheres Lebensalter. Theorie - Forschung - Praxis (pp. 31-50). Wiesbaden: Verlag für Sozialwissenschaften. DOI: 10.1007/978-3-531-91900-3.

29. Statistik Austria. (2012). IKT-Einsatz in Haushalten. Einsatz von Informations- und Kommunikations technologien in Haushalten 2012. Retrieved July 1, 2014, from http://www.statistik.at/web_de/statistiken /energie_umwelt_innovation_mobilitaet/informationsgesellschaft/ikt-einsatz_in_haushalten/index.html.

30. Statistik Austria. (2015). Internetnutzerinnen und Internetnutzer 2014. Retrieved June 3, 2015, from http://www.statistik.at/web_de/statistiken/energie_umwelt_innovation_mobilitaet/informationsges ellschaft/ikt-einsatz_in_haushalten/073636.html.

31. Sin, C. H. (2003). Interviewing in 'Place': The Socio-Spatial Construction of Interview Data. Area, 35(3), 305-312. DOI: 10.1111/1475-4762.00179. 
32. Strauss, A., \& Corbin, J. (1990). Grounded Theory. Grundlagen Qualitativer Sozialforschung. Weinheim: Beltz.

33. United Nations Development Programme (UNDP), Evaluation Office (EO). (2001). Essentials No. 5 September. Retrieved July 9, 2014, from http://web.undp.org/evaluation/documents/essentials_5.pdf.

34. Vollbrecht, R. (2009). Der medienbiographische Ansatz in der Altersmedienforschung. In B. Schorb, A. Hartung \& W. Reißmann (Eds.), Medien und höheres Lebensalter. Theorie - Forschung - Praxis (pp. 21-30). Wiesbaden: Verlag für Sozialwissenschaften. DOI: 10.1007/978-3-531-91900-3.

35. Wiederhold, A. (2015). Conducting Fieldwork at and Away from Home: Shifting Researcher Positionality with Mobile Interviewing Methods. Qualitative Research, 15(5), 600-615.

DOI: $10.1177 / 1468794114550440$. 